Revue

Revue de l'histoire des religions

de Ihistoire des religions

$1 \mid 2013$

Varia

\title{
Louis-Pierre SARDELLA, Demain, une revue catholique d'avant-garde (1905-1907)
}

Paris, Desclée de Brouwer (« Pages d'histoire »), 2011, 388 p., $24 \mathrm{~cm}, 32 €$, ISBN 978-2-220-06288-4.

\section{Ward De Pril}

\section{OpenEdition}

\section{Journals}

Édition électronique

URL : http://journals.openedition.org/rhr/8097

DOI : $10.4000 /$ rhr.8097

ISSN : 2105-2573

\section{Éditeur}

Armand Colin

\section{Édition imprimée}

Date de publication : 1 mars 2013

Pagination : 144-146

ISBN : 978-2-200-92863-6

ISSN : 0035-1423

Référence électronique

Ward De Pril, «Louis-Pierre Sardella, Demain, une revue catholique d'avant-garde (1905-1907) 》, Revue de I'histoire des religions [En ligne], 1 | 2013, mis en ligne le 12 avril 2013, consulté le 22 septembre 2020. URL : http://journals.openedition.org/rhr/8097 ; DOI : https://doi.org/10.4000/rhr.8097

Ce document a été généré automatiquement le 22 septembre 2020.

Tous droits réservés 


\section{Louis-Pierre SARDELLA, Demain, une revue catholique d'avant-garde (1905-1907)}

Paris, Desclée de Brouwer (« Pages d'histoire »), 2011, 388 p., $24 \mathrm{~cm}, 32 €$, ISBN 978-2-220-06288-4.

\section{Ward De Pril}

\section{RÉFÉRENCE}

Louis-Pierre SARDELLA, Demain, une revue catholique d'avant-garde (1905-1907), Paris, Desclée de Brouwer (« Pages d'histoire »), 2011, 388 p., 24 cm, 32 €, ISBN 978-2-220-06288-4.

1 Après son excellente monographie sur Mgr Eudoxe-Irénée Mignot (Cerf, 2004), LouisPierre Sardella (LPS) nous offre à nouveau un regard important et original sur le catholicisme français libéral et progressiste à l'époque de la crise moderniste, qui cherchait à se joindre au monde moderne dans tous ces aspects (politique, socioéconomique, intellectuel), mais en même temps désirait rester tout à fait loyal envers l'Église catholique. Une étude de l'hebdomadaire Demain nous introduit dans les idées courantes, concernant les grands thèmes politico-religieux, sociaux et intellectuels, non seulement du clergé, mais aussi et surtout du grand public laïc.

Le livre est composé de deux parties. Dans la première, les caractéristiques de la revue sont analysées. Demain fut fondé en octobre 1905 à Lyon. Le fondateur et directeur était Pierre Jay, un journaliste républicain libéral et catholique progressiste, qui s'opposait à l'ultramontanisme, l'antirépublicanisme et le cléricalisme de la majorité des catholiques français de l'époque. Les collaborateurs de Demain, P. Jay et quelques autres personnalités lyonnaises - comme Joseph Brugerette et Léon Chaine -, se présentaient parfois comme une "École de Lyon"; l'expression se justifie par des convictions partagées, notamment le libéralisme et l'antidreyfusisme, mais L.-P. Sardella met également l'accent sur les sensibilités différentes et l'absence de véritable doctrine 
commune. La nouvelle revue pouvait compter sur le soutien plus ou moins marqué de personnalités connues et influentes, comme Paul Sabatier, Henri Bremond, Georges Fonsegrive, le père Sertillanges, Ulysse Chevalier, Joseph Turmel, Marc Sangnier, Hermann Schell, Antonio Fogazzaro et Friedrich von Hügel. D'autre part, elle subissait l'hostilité déclarée des milieux intransigeants. L'objectif de Demain était surtout de faire évoluer le point de vue des catholiques à l'égard de la modernité politique, sociale et intellectuelle. Pour cela, la revue se voulait en premier lieu un espace de libre débat sur les questions concernant l'actualité religieuse, politique et socio-économique. Quant à l'orientation concrète de Demain, LPS est d'avis que le contenu idéologique est plus audacieux que la ligne du catholicisme libéral de l'époque de Léon XIII.

3 La seconde partie est consacrée aux grandes questions débattues dans la revue. Il s'agit tout d'abord des questions politico-religieuses, notamment la position des catholiques face à la République et lors du conflit de la séparation entre l'Église et l'État. Demain, et surtout son directeur $\mathrm{P}$. Jay, voulait défendre auprès de l'opinion catholique le libéralisme politique et refusait la notion de parti catholique. En continuité avec cette ligne politique, Demain se situe à l'avant-garde des catholiques qui font campagne pour l'acceptation de la loi de Séparation, jusqu'au vote du 9 décembre 1905. La motivation en est - entre autres - la conviction que la liberté retrouvée marquera le début d'une renaissance de l'Église: l'Église va perdre son image de puissance politique, pour apparaître comme une force morale; dans cet élan, elle introduira une série de réformes internes : Demain croit par exemple que les laïques recevront un rôle plus important dans les paroisses, qui deviendront des cellules de vie démocratique. Après la publication de l'encyclique Vehementer nos (11 février 1906), Demain devait abandonner cette position et se limiter à promouvoir l'idée d'une solution légale afin d'éviter l'affrontement entre la République et l'Église, conduisant selon la revue à l'impasse, avec des conséquences dramatiques pour l'Église de France.

4 Particulièrement intéressante est la position de Demain « dans la mêlée moderniste ». La nécessité d'accepter un espace de libre discussion dans l'Église et la légitimité de la critique forment le programme de base de Demain; aussi les rédacteurs montrent une grande liberté d'esprit dans les débats cruciaux du moment (sur la critique biblique, la philosophie et l'apologétique ou les sciences historiques). L'auteur caractérise la position de Demain comme une via media, une volonté de rester à l'intérieur de limites acceptables pour l'orthodoxie. Ainsi, dans son plaidoyer pour un renouvellement de l'apologétique, Demain préfère se référer à Newman (plutôt qu'à Blondel) pour justifier le primat accordé à l'expérience morale et donc à la conscience. De même, face aux grands problèmes posés par la mise en œuvre de la critique historique dans le domaine dogmatique, la revue met en avant l'œuvre de Mgr Duchesne, comme un exemple éminent de la capacité des catholiques à réaliser une œuvre scientifique, appliquant la critique historique à l'histoire de l'Église et, par conséquent, à l'histoire des dogmes. Le rapport entre dogme et histoire est réfléchi - à nouveau en référence à Newman - au travers d'une conception dynamique de la tradition dans son rapport à l'interprétation du message évangélique, mais en 1907 l'encyclique Pascendi fermera la perspective d'une telle via media.

Demain a pris une part active dans les discussions sur l'avenir des instituts catholiques en régime de séparation: devaient-ils se spécialiser en sciences religieuses (ce qui signifiait une répartition des tâches entre Église et État au niveau de l'enseignement supérieur), ou rester des universités complètes? C'est la stratégie de complémentarité 
de l'Église et de l'État qui est préférée par la plupart des correspondants de Demain. En même temps, ils demandent la liberté de l'activité scientifique dans les facultés libres, condition indispensable pour une "apologétique vivante» qui aurait une valeur indéniable dans les milieux intellectuels incroyants. À nouveau, ces propositions se heurtent à l'intransigeance du pape Pie X, qui rejette tout compromis avec l'État et l'ouverture de l'Église à la pensée contemporaine. « Cet échec montre qu'entre ceux qui posaient les questions et suggéraient des réformes et ceux qui détenaient les responsabilités dans l'Église, le contact était intellectuellement rompu» (p. 262). Il est évident que cette constatation d'un décalage entre les attentes des catholiques progressistes et la réponse romaine vaut d'autant plus en ce qui concerne les réformes internes de l'Église. Les demandes de limiter la centralisation romaine ou de renoncer au cléricalisme politique ne trouvaient pas une oreille favorable. Le dernier chapitre analyse la position de Demain par rapport aux questions de société : les fondements de la morale, le système éducatif, le syndicalisme, la législation sociale et Le Sillon. Peu après la publication du décret Lamentabili, la revue cesse d'exister (juillet 1907). Il n'y avait plus de marge à l'intérieur de l'Église pour y revendiquer la légitimité d'un travail de réconciliation avec l'esprit moderne.

6 En guise de conclusion, on peut dire que Demain constituait l'organe des catholiques progressistes lyonnais, marqués par une forte conscience du décalage entre l'Église et la conscience moderne et convaincus par conséquent de la nécessité d'une réforme des institutions et des mentalités catholiques. Son histoire illustre l'espoir remarquablement optimiste de ces milieux en un renouveau du catholicisme en France et le bouillonnement intellectuel qui les caractérisait, auquel ne fut mis un terme qu'au zénith de la crise moderniste, par les interventions magistérielles de 1907.

\section{AUTEURS}

\section{WARD DE PRIL}

Université de Louvain. 